\title{
Remifentanil-induced pronociceptive effect and its prevention with pregabalin
}

\author{
Hyong Rae Jo ${ }^{1}$, Young Keun Chae ${ }^{1}$, Yong Ho Kim ${ }^{1}$, Hong Seok Chai ${ }^{1}$, Woo Kyung Lee ${ }^{1}$, Sun Soon Choi ${ }^{2, *}$, \\ Jin Hye Min ${ }^{1}$, In Gyu Choi ${ }^{1}$, and Young Soon $\mathrm{Choi}^{1}$ \\ ${ }^{1}$ Department of Anesthesiology and Pain Medicine, Myongji Hospital, Kwandong University Medical School, Goyang, Korea, \\ ${ }^{2}$ The Nicholas C. Petris Center on Health Care Markets and Consumer Welfare, School of Public Health, University of California, \\ Berkeley, USA
}

Background: Experimental and clinical studies have suggested that remifentanil probably causes acute tolerance or postinfusion hyperalgesia. This study was designed to confirm whether remifentanil given during propofol anesthesia induced postoperative pain sensitization, and we wanted to investigate whether pregabalin could prevent this pronociceptive effect.

Methods: Sixty patients who were scheduled for total abdominal hysterectomy were randomly allocated to receive (1) a placebo as premedication and an intraoperative saline infusion (control group), (2) a placebo as premedication and an intraoperative infusion of remifentanil at a rate of $3-4 \mathrm{ng} / \mathrm{ml}$ (remifentanil group), or (3) pregabalin $150 \mathrm{mg}$ as premedication and an intraoperative infusion of remifentanil at a rate of $3-4 \mathrm{ng} / \mathrm{ml}$ (pregabalin-remifentanil group). Postoperative pain was controlled by titration of fentanyl in the postanesthetic care unit (PACU), followed by patientcontrolled analgesia (PCA) with fentanyl. The patients were evaluated using the visual analogue scale (VAS) for pain scores at rest and after cough, consumption of fentanyl, sedation score and any side effects that were noted over the $48 \mathrm{~h}$ postoperative period.

Results: The fentanyl titration dose given in the PACU was significantly larger in the remifentanil group as compared with those of the other two groups. At rest, the VAS pain score in the remifentanil group at $2 \mathrm{~h}$ after arrival in the PACU was significantly higher than those in the other two groups.

Conclusions: The results of this study show that remifentanil added to propofol anesthesia causes pain sensitization in the immediate postoperative period. Pretreatment with pregabalin prevents this pronociceptive effect and so this may be useful for the management of acute postoperative pain when remifentanil and propofol are used as anesthetics. (Korean J Anesthesiol 2011; 60: 198-204)

Key Words: Hyperalgesia, Pregabalin, Remifentanil, Tolerance.

Received: August 25, 2010. Revised: October 28, 2010. Accepted: October 28, 2010.

Corresponding author: Young Soon Choi, M.D., Department of Anesthesiology and Pain Medicine, Myongji Hospital, 697-24, Hwajeong-dong, Goyang 412-270, Korea. Tel: 82-31-810-6203, Fax: 82-31-810-6209, E-mail: ysc1003@yahoo.co.kr

* Statistician

(c) This is an open-access article distributed under the terms of the Creative Commons Attribution Non-Commercial License (http:// creativecommons.org/licenses/by-nc/3.0/), which permits unrestricted non-commercial use, distribution, and reproduction in any medium, provided the original work is properly cited. 


\section{Introduction}

Opioids are the main analgesics that are used for treating moderate to severe pain. However, many studies have suggested that they paradoxically result in postinfusion hyperalgesia and tolerance $[1,2]$. Remifentanil is an ultra short-acting $\mu$-opioid receptor agonist that is commonly used to supplement general anesthesia. Some previous studies have failed to confirm $[3,4]$, remifentanil causes a similar phenomenon after intraoperative infusion [5-7]. A recent study showed that previous exposure to remifentanil enhanced the mechanical hyperalgesia after a second surgery, and those authors suggested that preventive measures are needed to avoid latent sensitization in future surgeries [8].

Opioid-induced pronociceptive effects are thought to result from the central and peripheral nervous system sensitization and they share the same mechanisms with that of the hyperalgesia associated with nerve injury $[9,10]$. This suggests that preemptive treatment with drugs that are effective for the management of neuropathic pain may prevent or reduce the pain sensitization induced by opioids.

Pregabalin is a 3 -substituted analogue of $\gamma$-amino butyric acid, and it was developed as a new-generation antiepileptic drug with fewer side effects. It has been approved for the treatment of neuropathic pain and anxiety disorder $[11,12]$. It has been shown to reduce hyperalgesia and allodynia in a preclinical model $[13,14]$. Gabapentin, which is a close structural relative of pregabalin and it has a similar mechanism of action, has been documented to prevent the development of tolerance and hyperalgesia elicited by opioids in animal model studies $[15,16]$. However, well-designed clinical studies on the effect of gabapentinoids for the prevention of opioid-induced pain sensitization have not yet been conducted. The present study was designed to test the hypothesis that intraoperative remifentanil infusion during propofol anesthesia induced postoperative pain sensitization as indicated by a higher pain score or a larger fentanyl dose is needed to achieve satisfactory analgesia and that preemptive treatment with pregabalin could prevent this pain sensitization.

\section{Materials and Methods}

After receiving ethical committee approval, written informed consent was obtained from 60 ASA physical status I-II patients who were treated at our hospital. All of them were scheduled for non-malignant total abdominal hysterectomy with a supravaginal, horizontal approach under general anesthesia. The exclusion criteria were if patients had more than a $35 \mathrm{~kg} /$ $\mathrm{m}^{2}$ body mass index, the inability to use PCA, contraindications to any of drugs used in the study and a history of chronic pain, opioids use within 3 months before surgery, drug or alcohol addiction and kidney dysfunction.

Before the study began, the patients were randomly allocated according to a computer generated random number sequence into one of three groups: (1) the control group in which the patients were given an identical-looking placebo orally as premedication and an intraoperative normal saline infusion, (2) the remifentanil group in which the patients were given an identical-looking placebo orally as premedication and an intraoperative infusion of remifentanil at a rate of 3-4 $\mathrm{ng} /$ $\mathrm{ml}$, or (3) pregabalin-remifentanil group in which the patients were given pregabalin $150 \mathrm{mg}$ orally as premedication and intraoperative infusion of remifentanil at a rate of $3-4 \mathrm{ng} / \mathrm{ml}$.

The evening before surgery, the patients were instructed about the use of a PCA device (Accumate $1000^{\circledR}$, Woo Young Medical, Korea), a four point verbal rating scale for pain $(0=$ no pain, $1=$ slight and tolerable pain, $2=$ moderate pain, $3=$ severe pain $)$ and a 100 -mm VAS for pain $(0=$ no pain to $100=$ worst imaginable pain). One hour before surgery, the patients received pregabalin $150 \mathrm{mg}$ or an identical-looking placebo orally as premedication. Before the induction of anesthesia, a nurse who was not participating in the investigation prepared remifentanil or normal saline solution syringes. The personnel involved in the patient management and data collection did not know the group assignment.

Upon the patients' arrival in the operating room, the patients were monitored by pulse oximetry, electrocardiography and noninvasive blood pressure (BP). Anesthesia was induced with propofol at an initial target-effect site concentration of $5 \mu \mathrm{g} / \mathrm{ml}$ and remifentanil at a target-effect site concentration of $4 \mathrm{ng} / \mathrm{ml}$ (Orchestra ${ }^{\circledR}$, Fresenius Vial, France). After loss of consciousness, the patients received a bolus of vecuronium 1.2 $\mathrm{mg} / \mathrm{kg}$ and then they were ventilated to obtain normocapnia with $50 \% \mathrm{~N}_{2} \mathrm{O}$ in oxygen.

General anesthesia was maintained with a continuous infusion of propofol (a target-effect site concentration of $2-6 \mu \mathrm{g} / \mathrm{ml}$ ), and this was titrated to maintain the Bispectral Index (BIS) between 45 and 55 . The target remifentanil concentration was adjusted between $3 \mathrm{ng} / \mathrm{ml}$ and $4 \mathrm{ng} / \mathrm{ml}$, according to the patient's vital signs. Twenty minutes before the anticipated end of surgery, remifentanil or saline was discontinued and all the patients received an injection of IV fentanyl $25 \mu \mathrm{g}$ and ondansetron $4 \mathrm{mg}$. During the closure of skin, the propofol and $\mathrm{N}_{2} \mathrm{O}$ were discontinued and the neuromuscular block was antagonized with glycopyrrolate $0.4 \mathrm{mg}$ and pyridostigmine $15 \mathrm{mg}$. The endotracheal tube was removed when the patient recovered consciousness and spontaneous respiration. The total doses of propofol and remifentanil infused during the anesthesia and the duration of anesthesia and surgery were recorded. The times from the end of surgery to awakening (opening their eyes 
on a verbal command), recovery of spontaneous ventilation and tracheal extubation were also noted.

The patients were transferred to the PACU and they remained in the unit for at least $1 \mathrm{~h}$. Postoperative pain was initially controlled by titration of IV fentanyl, which was given at every 3 minute interval in $25 \mu$ g increments until the verbal rating pain score was less than 2. Fentanyl titration was discontinued if the patient had peripheral oxygen saturation less than $92 \%$, a respiration rate less than 10 breaths/min or a sedation score greater than 4 . Subsequently, analgesia was continued with PCA that delivered fentanyl $0.3 \mu \mathrm{g} / \mathrm{kg}$ as an IV bolus, with a lockout interval of $5 \mathrm{~min}$ and no background infusion for $48 \mathrm{~h}$. The sedation score was assessed by the Ramsay sedation scale ( $1=$ anxious and agitated or restless, or both, $2=$ cooperative, oriented and tranquil, 3 = responds to command only, $4=$ asleep, but has a brisk response to a light glabellar tap or a loud auditory stimulus, 5 = asleep, but has a sluggish response to a light glabellar tap or loud auditory stimulus, 6 = asleep, no response). The patients were evaluated for the VAS pain scores (at rest and after cough), heart rate (HR), BP, sedation score, respiration rate and the fentanyl consumption by PCA over the $48 \mathrm{~h}$ postoperative period. The fentanyl titration dose was the amount of fentanyl needed to obtain adequate pain relief (a verbal rating pain sore less than 2) in the PACU and this did not include the intraoperative fentanyl bolus. The cumulative fentanyl consumption was the amount of fentanyl administrated by the PCA device, with excluding titration. The occurrence of any side effects such as nausea, vomiting, dry mouth, pruritus, somnolence, dizziness, headache and swelling of limbs was recorded during the study period. Hypotension (mean BP $<60 \mathrm{mmHg}$ ) or bradycardia ( $\mathrm{HR}<45$ beats $/ \mathrm{min}$ ) was treated with $5 \mathrm{mg}$ ephedrine or atropine $0.5 \mathrm{mg}$. The patients were telephoned on the first and third month after their discharge from the hospital and they were interviewed to inquire about their present pain score and the occurrence of any side effects.

The amount of fentanyl given by titration in the PACU to control the acute postoperative pain was considered the primary outcome of our study. From our initial pilot observations, we estimated the standard deviation within each group to be approximately 90 and the effect size was equal to approximately 0.42. For estimating the priori sample size, we used $\mathrm{G}^{*}$ power software, version 3.0.10 for Windows and nineteen patients in each treatment group would be required when the $\alpha$ error was presumed to be 0.05 . Post hoc calculation of the achieved power was 0.81 . Based on our own experience using this experimental setting, we expected a dropout rate of $5 \%$. Therefore, the total number of patients was set at 60 persons. The demographic characteristics, the duration of surgery and anesthesia, the fentanyl consumption and the pain VAS scores at each time point were compared among the three groups using one-way analysis of variance. For post hoc comparisons, we used the Turkey test, as needed. The Fisher's exact test or $\chi^{2}$ test was used for categorical variables. The hemodynamic variables were analyzed with two-way analysis of variance for repeated measures. For data analysis, we used SPSS software (Version 14.0 for Windows) and statistical significance throughout the study was defined as $\mathrm{P}$ value $<0.05$.

\section{Results}

All the patients were able to complete the study and the groups were comparable with respect to the demographic characteristics, the duration of surgery and anesthesia, the total consumption of propofol and remifentanil and the recovery times (Table 1).

The fentanyl titration dose given in the PACU was significantly different between the groups $(\mathrm{F}=7.744, \mathrm{P}=0.001$ ) (Fig. 1). Post hoc analysis demonstrated that the remifentanil group required the greatest amount of fentanyl $(\mathrm{P}=0.002$ for the control group,

Table 1. Demographic Characteristics and the Perioperative Data

\begin{tabular}{lccc}
\hline \multicolumn{1}{c}{ Variable } & Control $(\mathrm{n}=20)$ & Remifentanil $(\mathrm{n}=20)$ & Pregabalin-Remifentanil $(\mathrm{n}=20)$ \\
\hline Age $(\mathrm{yr})$ & $44.8 \pm 5.4$ & $46.0 \pm 5.2$ & $46.2 \pm 6.6$ \\
Weight $(\mathrm{kg})$ & $62.5 \pm 6.9$ & $61.0 \pm 9.5$ & $60.2 \pm 7.9$ \\
Height $(\mathrm{cm})$ & $159.0 \pm 5.1$ & $155.7 \pm 4.7$ & $157.4 \pm 5.9$ \\
ASA (I/I) & $15 / 5$ & $17 / 3$ & $17 / 3$ \\
Duration of surgery (min) & $122.3 \pm 35.0$ & $120.3 \pm 43.2$ & $134.4 \pm 27.1$ \\
Duration of anesthesia (min) & $147.0 \pm 33.3$ & $145.0 \pm 40.7$ & $158.0 \pm 27.3$ \\
Propofol dose (mg/min) & $7.1 \pm 1.5$ & $6.2 \pm 1.3$ & $6.3 \pm 1.4$ \\
Remifentanil dose $(\mu \mathrm{gg} / \mathrm{min})$ & & $6.5 \pm 1.5$ & $6.3 \pm 1.7$ \\
Recovery time (min) & & & \\
$\quad$ Eye opening & $6.3 \pm 4.3$ & $4.3 \pm 3.7$ & $6.3 \pm 3.9$ \\
Spontaneous respiration & $2.7 \pm 2.1$ & $2.0 \pm 1.6$ & $3.8 \pm 2.8$ \\
Extubation & $7.0 \pm 4.5$ & $4.7 \pm 3.9$ & $7.0 \pm 3.7$
\end{tabular}

Values are presented as mean \pm SD or the number of patients. 


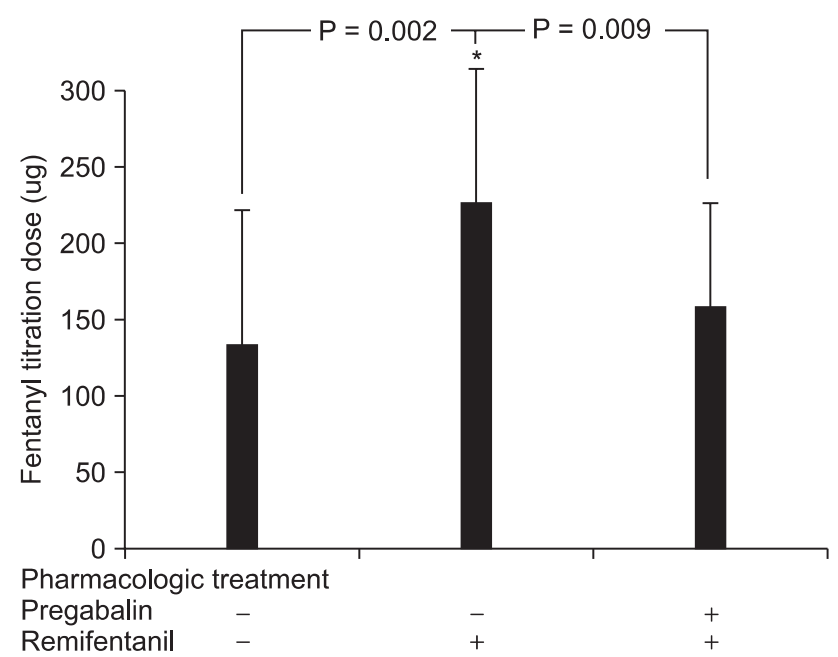

Fig. 1. The fentanyl titration dose in the postanesthetic care unit. Values are presented as mean $\pm \mathrm{SD}$. $* \mathrm{P}<0.05$, when comparing the remifentanil group with the control group and the pregabalinremifentanil group.
$\mathrm{P}=0.009$ for the pregabalin-remifentanil group). No significant differences between the three groups were found for fentanyl consumption by PCA over the $48 \mathrm{~h}$ postoperative period (Table 2).

The VAS scores at rest (Fig. 2A) were similar in the three groups during the $48 \mathrm{~h}$ postoperative period except at $2 \mathrm{~h}$ after arrival at the PACU at which time the VAS score in the remifentanil group (36.5 $\pm 14.6 \mathrm{~mm})$ was significantly higher than those in the control group $(26.5 \pm 9.3 \mathrm{~mm}, \mathrm{P}=0.016)$ and the pregabalin-remifentanil group $(27.0 \pm 8.0 \mathrm{~mm}, \mathrm{P}=0.023)$. The VAS scores after cough of remifentanil group (Fig. 2B) at $2 \mathrm{~h}$ after arrival at the PACU were higher than those of other groups, although there were no significant differences between the groups ( $\mathrm{P}=0.109$ for the control group, $\mathrm{P}=0.112$ for the pregabalin-remifentanil group).

There were no significant differences in the incidence of side effects throughout the study among the three groups (Table 3). Two patients in the pregabalin-remifentanil group during the operation experienced bradycardia ( 45 beats/min) without hypotension, but the hemodynamic variables throughout

Table 2. Fentanyl Consumption

\begin{tabular}{lccc}
\hline & Control $(\mathrm{n}=20)$ & Remifentanil $(\mathrm{n}=20)$ & Pregabalin-Remifentanil $(\mathrm{n}=20)$ \\
\hline By titration in PACU $(\mu \mathrm{g})$ & $133.8 \pm 87.8$ & $227.5 \pm 88.1^{*}$ & $148.8 \pm 64.6$ \\
By PCA $(\mu \mathrm{g})$ & & & \\
$2 \mathrm{~h}$ & $108.5 \pm 59.5$ & $138.8 \pm 73.6$ & $127.4 \pm 57.6$ \\
$3 \mathrm{~h}$ & $150.0 \pm 73.4$ & $211.9 \pm 122.5$ & $174.6 \pm 78.8$ \\
$6 \mathrm{~h}$ & $231.3 \pm 120.1$ & $307.7 \pm 171.9$ & $278.8 \pm 130.4$ \\
$24 \mathrm{~h}$ & $413.3 \pm 256.8$ & $568.6 \pm 336.4$ & $560.0 \pm 234.2$ \\
$48 \mathrm{~h}$ & $651.6 \pm 367.5$ & $756.5 \pm 502.4$ & 0.121 \\
\hline
\end{tabular}

Values are presented as mean \pm SD. PCA: patient-controlled analgesia, PACU: postanesthetic care unit. *P $<0.05$, when comparing the remifentanil group with the control group and the pregabalin-remifentanil group.

A

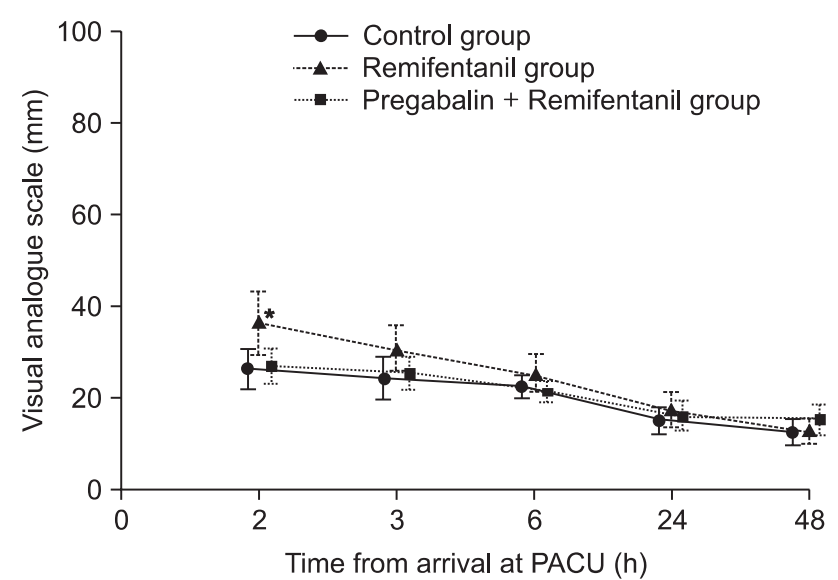

B

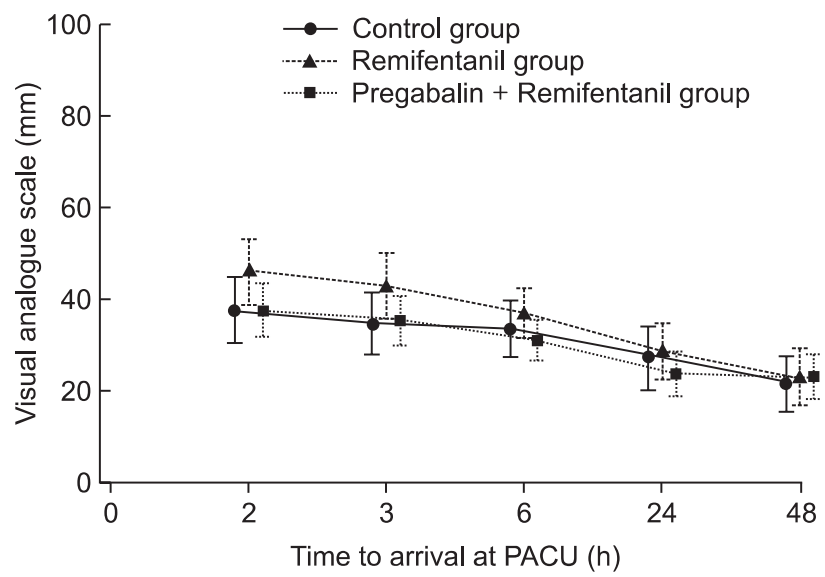

Fig. 2. The visual analogue scale (VAS) pain scores at rest (A) and after cough (B) over the $48 \mathrm{~h}$ postoperative period after arrival in the postoperative care unit (PACU). Values are presented as mean $\pm \mathrm{SD}$. ${ }^{\mathrm{P}}<0.05$, when comparing the remifentanil group with the control group and the pregabalin-remifentanil group. 
the study and the postoperative sedation scores did not differ among the three groups (Table 4). None of the patients complained about the occurrence of delayed pain and any side effects on the first and third month after discharge from the hospital.

\section{Discussion}

The results of the present investigation showed that intraoperative remifentanil infusion during propofol anesthesia increased the fentanyl titration dose required to achieve satisfactory analgesia, and it increased the pain score. This phenomenon was transient and it occurred in the early postoperative period. The preoperative orally administrated pregabalin $150 \mathrm{mg}$ prevented fentanyl overconsumption and it

Table 3. Incidence of Side Effects

\begin{tabular}{lccc}
\hline \multicolumn{1}{c}{ Side effect } & $\begin{array}{c}\text { Control } \\
(\mathrm{n}=20)\end{array}$ & $\begin{array}{c}\text { Remifentanil } \\
(\mathrm{n}=20)\end{array}$ & $\begin{array}{c}\text { Pregabalin- } \\
\text { Remifentanil } \\
(\mathrm{n}=20)\end{array}$ \\
\hline Somnolence & 0 & 0 & 2 \\
Headache & 0 & 1 & 1 \\
Nausea & 1 & 4 & 4 \\
Vomiting & 0 & 0 & 0 \\
Dizziness & 1 & 1 & 1 \\
Dry mouth & 2 & 1 & 0 \\
Pruritus & 0 & 1 & 0 \\
Swelling of limbs & 0 & 0 & 0 \\
\hline
\end{tabular}

Values are presented as the number of patients. reduced the higher pain intensity induced by remifentanil.

The possible explanation for the larger fentanyl titration dose and higher pain score in the remifentanil group compared to that in control group would be the development of acute tolerance or postinfusion hyperalgesia. Guignard et al. [5] reported that a large dose of intraoperatively infused remifentanil $(0.3 \mu \mathrm{g} / \mathrm{kg} / \mathrm{min})$ caused acute opioid tolerance and hyperalgesia. Joly et al. [6] found that a large dose of intraoperative remifentanil $(0.4 \mu \mathrm{g} / \mathrm{kg} / \mathrm{min})$ increased the periincisional wound hyperalgesia and allodynia to stimulation with von Frey hair. Our study differed according to two points. First, the remifentanil infusion rate was lower than that of the above mentioned studies. The remifentanil-induced pronociceptive effect seems to be dose dependent [8], but it has been previously documented that a low dose of remifentanil infusion $(0.1 \mu \mathrm{g} /$ $\mathrm{kg} / \mathrm{min}$ ) could cause acute tolerance [7]. Second, the fentanyl requirement and pain score were increased only during the early postoperative period and any delayed hyperalgesia did not occur.

Many drugs have been tried to attenuate or prevent the expression of opioid-induced tolerance and hyperalgesia $[10,17]$, including gabapentinoids $[15,16]$. Van Elstraete et al. [16] suggested that the short-term use of systemic fentanyl in rats induced a delayed and sustained hyperalgesia, and that intraperitoneal and intrathecal gabapentin prevented this phenomenon. Gilron et al. [15] also found that gabapentin not only potentiated morphine's antinociceptive effect in morphine tolerant rats, but it also attenuated the development

Table 4. Mean Arterial Pressure, Heart Rate and Ramsey Sedation Score

\begin{tabular}{|c|c|c|c|}
\hline Variable & Control $(n=20)$ & Remifentanil $(\mathrm{n}=20)$ & Pregabalin-Remifentanil $(n=20)$ \\
\hline \multicolumn{4}{|c|}{ Mean arterial pressure (mmHg) } \\
\hline At arrival in the PACU & $93.1 \pm 12.5$ & $102.9 \pm 15.7$ & $97.0 \pm 17.7$ \\
\hline $2 \mathrm{~h}$ & $91.7 \pm 12.6$ & $97.7 \pm 11.5$ & $89.8 \pm 10.5$ \\
\hline $3 \mathrm{~h}$ & $89.6 \pm 10.1$ & $95.6 \pm 13.2$ & $91.1 \pm 11.8$ \\
\hline $6 \mathrm{~h}$ & $89.9 \pm 9.8$ & $97.1 \pm 11.8$ & $90.0 \pm 11.0$ \\
\hline $24 \mathrm{~h}$ & $83.9 \pm 20.9$ & $90.9 \pm 8.7$ & $93.4 \pm 22.6$ \\
\hline $48 \mathrm{~h}$ & $83.7 \pm 9.7$ & $87.7 \pm 9.0$ & $83.8 \pm 12.6$ \\
\hline \multicolumn{4}{|l|}{ Heart rate (beats/min) } \\
\hline At arrival in the PACU & $61.7 \pm 13.2$ & $67.8 \pm 10.7$ & $71.5 \pm 15.0$ \\
\hline $2 \mathrm{~h}$ & $71.5 \pm 12.6$ & $70.1 \pm 9.6$ & $71.5 \pm 10.5$ \\
\hline $3 \mathrm{~h}$ & $71.7 \pm 12.7$ & $68.8 \pm 8.5$ & $70.8 \pm 9.8$ \\
\hline $6 \mathrm{~h}$ & $70.1 \pm 10.4$ & $71.9 \pm 10.9$ & $75.2 \pm 12.9$ \\
\hline $24 \mathrm{~h}$ & $71.8 \pm 7.8$ & $71.7 \pm 7.9$ & $72.3 \pm 9.5$ \\
\hline $48 \mathrm{~h}$ & $74.4 \pm 6.7$ & $7.3 .4 \pm 7.8$ & $73.0 \pm 9.9$ \\
\hline \multicolumn{4}{|c|}{ Sedation score $(1 / 2 / 3 / 4 / 5 / 6)$} \\
\hline At arrival in the PACU & $3 / 0 / 12 / 5 / 0 / 0$ & $2 / 3 / 10 / 5 / 0 / 0$ & $1 / 1 / 12 / 6 / 0 / 0$ \\
\hline $2 \mathrm{~h}$ & $0 / 15 / 4 / 1 / 0 / 0$ & $2 / 15 / 3 / 0 / 0 / 0$ & $0 / 17 / 3 / 0 / 0 / 0$ \\
\hline $3 \mathrm{~h}$ & $0 / 16 / 4 / 0 / 0 / 0$ & $1 / 17 / 2 / 0 / 0 / 0$ & $0 / 18 / 2 / 0 / 0 / 0$ \\
\hline $6 \mathrm{~h}$ & $17 / 3 / 0 / 0 / 0 / 0$ & $18 / 2 / 0 / 0 / 0 / 0$ & $18 / 2 / 0 / 0 / 0 / 0$ \\
\hline $24 \mathrm{~h}$ & $0 / 17 / 3 / 0 / 0 / 0$ & $1 / 17 / 2 / 0 / 0 / 0$ & $0 / 19 / 1 / 0 / 0 / 0$ \\
\hline $48 \mathrm{~h}$ & $17 / 3 / 0 / 0 / 0 / 0$ & $19 / 1 / 0 / 0 / 0 / 0$ & $19 / 1 / 0 / 0 / 0 / 0$ \\
\hline
\end{tabular}

Values are presented as mean \pm SD or the number of patients. PACU: postanesthetic care unit. 
of morphine tolerance. Pregabalin probably has the same cellular mechanism of action as that of gabapentin, but pregabalin has a more favorable pharmacokinetic profile [11]. This suggests that pregabalin may be useful in patients with pain sensitization induced by opioids. Although there were no significant differences between the three groups for the fentanyl consumption by PCA in our study, the fentanyl titration dose and the postoperative pain score in the pregabalin-remifentanil group were significantly lower than those of the remifentanil group, and they were comparable to those of the control group in the immediate postoperative period. A possible explanation would be that the postoperative pain was controlled by titration of fentanyl in the PACU until the verbal rating pain score was less than 2, and this was followed by PCA. The total fentanyl consumption in the pregabalin-remifentanil group during the $2 \mathrm{~h}$ postoperative period was also significantly lower than that of the remifentanil group. So the results could be explained by the modulatory effect of pregabalin on the pronociceptive effect induced by remifentanil.

The exact mechanisms that may account for the opioidinduced pronociceptive effect remain to be unraveled. Multiple central and peripheral pathways and mechanisms have been studied, including the sensitization of the primary afferent neurons [18], translocation and activation of protein kinase $\mathrm{C}$ [19], production of nitric oxide [9], the activation of N-methylD-aspartate (NMDA) receptors [20], the enhanced production and release of excitatory amino acids [21] and an increase of spinal dynorphin [22]. Pregabalin has been demonstrated to bind to the $\alpha_{2}-\delta$ auxiliary subunit of the presynaptic voltagegated calcium channel $[23,24]$. Yet this subunit has not been directly associated with the development of opioid tolerance and hyperalgesia. The underlying hypothesis is that by its binding to the $\alpha_{2}-\delta$ subunit, pregabalin inhibits the release of presynaptic excitatory neurotransmitters and it may oppose the release induced by opioid exposure.

There has been a report showing that perioperative administration of pregabalin was associated with a higher incidence of dizziness, blurred vision and headache during the first $24 \mathrm{~h}$ after surgery [25], but pregabalin $150 \mathrm{mg}$ did not increase any side effects or the recovery times in our results. Although the fentanyl requirement in the PACU was significantly higher in the remifentanil group, there were no significant differences of the opioid-related adverse effects, including postoperative nausea and vomiting (PONV). One explanation would be that all the patients were given an injection of IV ondansetron $4 \mathrm{mg}$ before the end of surgery, and the anesthesia was maintained with propofol.

Propofol has been reported to inhibit NMDA receptor [26], but it has also been reported to produce hyperalgesia through the activation of the $\gamma$-amino-butyric acid $\mathrm{A}\left(\mathrm{GABA}_{\mathrm{A}}\right)$ receptor in the endogenous pain descending inhibition at the superspinal level [27]. Therefore, it is conceivable that propofol may have some modulatory effects on the tolerance and postinfusion hyperalgesia induced by opioid. Singler et al. [28] reported that propofol at the subhypnotic dose led to a delay and weakening of the antinociceptive effect after remifentanil infusion in human volunteers. However, they found that postinfusion hyperalgesia was observed even after remifentanil was combined with propofol. Our results also showed that remifentanil infusion during propofol anesthesia caused pain sensitization in the early postoperative period. However, since our study did not evaluate the effect of propofol on opioidinduced pronociception, no conclusion can be derived and future studies on this are needed.

In summary, we found that an intraoperative remifentanil infusion that is given during propofol-based anesthesia caused a larger analgesic requirement to achieve satisfactory analgesia and a higher pain score in the early postoperative period. We also found that preemptive treatment with pregabalin prevented the pain sensitization induced by remifentanil. This information suggests that pregabalin given as premedication will be able to suppress the development of the pain sensitization processes induced by remifentanil and it may be a useful adjunctive agent for the management of acute postoperative pain when an intraoperative remifentanil infusion is required. Further studies are necessary to investigate the optimal dose and to explain the mechanisms of action of pregabalin on opioid-induced pain sensitization.

\section{References}

1. Angst MS, Clark JD. Opioid-induced hyperalgesia: a qualitative systematic review. Anesthesiology 2006; 104: 570-87.

2. Anand KJ, Willson DF, Berger J, Harrison R, Meert KL, Zimmerman J, et al. Tolerance and withdrawal from prolonged opioid use in critically ill children. Pediatrics 2010; 125: e1208-25.

3. Cortínez LI, Brandes V, Muñoz HR, Guerrero ME, Mur M. No clinical evidence of acute opioid tolerance after remifentanil-based anaesthesia. Br J Anaesth 2001; 87: 866-9.

4. Schraag S, Checketts MR, Kenny GN. Lack of rapid development of opioid tolerance during alfentanil and remifentanil infusions for postoperative pain. Anesth Analg 1999; 89: 753-7.

5. Guignard B, Bossard AE, Coste C, Sessler DI, Lebrault C, Alfonsi P, et al. Acute opioid tolerance: intraoperative remifentanil increases postoperative pain and morphine requirement. Anesthesiology 2000; 93: 409-17.

6. Joly V, Richebe P, Guignard B, Fletcher D, Maurette P, Sessler DI, et al. Remifentanil-induced postoperative hyperalgesia and its prevention with small-dose ketamine. Anesthesiology 2005; 103 : 147-55.

7. Vinik HR, Kissin I. Rapid development of tolerance to analgesia during remifentanil infusion in humans. Anesth Analg 1998; 86: 
1307-11.

8. Cabañero D, Campillo A, Célérier E, Romero A, Puig MM. Pronociceptive effects of remifentanil in a mouse model of postsurgical pain: effect of a second surgery. Anesthesiology 2009; 111: 1334-45.

9. Mao J, Price DD, Mayer DJ. Mechanisms of hyperalgesia and morphine tolerance: a current view of their possible interactions. Pain 1995; 62: 259-74.

10. Chu LF, Angst MS, Clark D. Opioid-induced hyperalgesia in humans: molecular mechanisms and clinical considerations. Clin J Pain 2008; 24: 479-96.

11. Guay DR. Pregabalin in neuropathic pain: a more "pharmaceutically elegant" gabapentin? Am J Geriatr Pharmacother 2005; 3: 274-87.

12. Lauria-Horner BA, Pohl RB. Pregabalin: a new anxiolytic. Expert Opin Investig Drugs 2003; 12: 663-72.

13. Chizh BA, Göhring M, Tröster A, Quartey GK, Schmelz M, Koppert W. Effects of oral pregabalin and aprepitant on pain and central sensitization in the electrical hyperalgesia model in human volunteers. Br J Anaesth 2007; 98: 246-54.

14. Field MJ, Bramwell S, Hughes J, Singh L. Detection of static and dynamic components of mechanical allodynia in rat models of neuropathic pain: are they signalled by distinct primary sensory neurones? Pain 1999; 83: 303-11.

15. Gilron I, Biederman J, Jhamandas K, Hong M. Gabapentin blocks and reverses antinociceptive morphine tolerance in the rat pawpressure and tail-flick tests. Anesthesiology 2003; 98: 1288-92.

16. Van Elstraete AC, Sitbon P, Mazoit JX, Benhamou D. Gabapentin prevents delayed and long-lasting hyperalgesia induced by fentanyl in rats. Anesthesiology 2008; 108: 484-94.

17. Lee EM, Lee H, Kim CH, Lee GY. A double-blinded, randomized, placebo controlled study of the effect a small dose of ketamine has on postoperative pain of sevoflurane-remifentanil anesthesia. Korean J Anesthesiol 2008; 54: 146-51.

18. Aley KO, Levine JD. Dissociation of tolerance and dependence for opioid peripheral antinociception in rats. J Neurosci 1997; 17: 3907 12.

19. Célérier E, Simonnet G, Maldonado R. Prevention of fentanyl- induced delayed pronociceptive effects in mice lacking the protein kinase Cgamma gene. Neuropharmacology 2004; 46: 264-72.

20. Zhao M, Joo DT. Enhancement of spinal N-methyl-D-aspartate receptor function by remifentanil action at delta-opioid receptors as a mechanism for acute opioid-induced hyperalgesia or tolerance. Anesthesiology 2008; 109: 308-17.

21. Wen ZH, Chang YC, Cherng CH, Wang JJ, Tao PL, Wong CS. Increasing of intrathecal CSF excitatory amino acids concentration following morphine challenge in morphine-tolerant rats. Brain Res 2004; 995: 253-9.

22. Campillo A, González-Cuello A, Cabañero D, Garcia-Nogales $P$, Romero A, Milanés MV, et al. Increased spinal dynorphin levels and phospho-extracellular signal-regulated kinases 1 and 2 and c-Fos immunoreactivity after surgery under remifentanil anesthesia in mice. Mol Pharmacol 2010; 77: 185-94.

23. Joshi I, Taylor CP. Pregabalin action at a model synapse: binding to presynaptic calcium channel alpha2-delta subunit reduces neurotransmission in mice. Eur J Pharmacol 2006; 553: 82-8.

24. Fink K, Dooley DJ, Meder WP, Suman-Chauhan N, Duffy S, Clusmann $\mathrm{H}$, et al. Inhibition of neuronal $\mathrm{Ca}(2+)$ influx by gabapentin and pregabalin in the human neocortex. Neuropharmacology 2002; 42: 229-36.

25. Jokela R, Ahonen J, Tallgren M, Haanpää M, Korttila K. A randomized controlled trial of perioperative administration of pregabalin for pain after laparoscopic hysterectomy. Pain 2008; 134: 106-12.

26. Kingston S, Mao L, Yang L, Arora A, Fibuch EE, Wang JQ. Propofol inhibits phosphorylation of N-methyl-D-aspartate receptor NR1 subunits in neurons. Anesthesiology 2006; 104: 763-9.

27. Wang QY, Cao JL, Zeng YM, Dai TJ. GABAA receptor partially mediated propofol-induced hyperalgesia at superspinal level and analgesia at spinal cord level in rats. Acta Pharmacol Sin 2004; 25: 1619-25.

28. Singler B, Tröster A, Manering N, Schüttler J, Koppert W. Modulation of remifentanil-induced postinfusion hyperalgesia by propofol. Anesth Analg 2007; 104: 1397-403. 